\title{
In Vivo Release of Dopamine by Perfusion of 1-Methyl-4- Phenylpyridinium Ion in the Striatum with a Microdialysis Technique
}

\author{
Toshio Obata ${ }^{1}$, Yasumitsu Yamanaka ${ }^{1}$ and Chuang C. Chiueh ${ }^{2}$ \\ 'Department of Pharmacology, Oita Medical University, 1-1, Idaigaoka, Hazama-machi, Oita 879-55, Japan \\ ${ }^{2}$ National Institute of Mental Health, Bethesda, Maryland 20892, U.S.A. \\ Received July 16, $1992 \quad$ Accepted September 22, 1992
}

\begin{abstract}
We examined the effects of 1-methyl-4-phenylpyridinium ion $\left(\mathrm{MPP}^{+}\right)$on the release of DA in rat striatum by the in vivo microdialysis technique. For this study, we made a suitable microdialysis probe from a $22-\mathrm{G}$ needle, microliter pipette tip, silica tube and polyethylene tube. Such a repairable microdialysis probe can be easily made from readily available and inexpensive materials. DA release, as determined by the 3-methoxytyramine level, was dose-dependently increased by MPP ${ }^{+}(1-10$ $\mathrm{mM}$ ). Only the presence of a $1 \mathrm{mM}$ concentration of $\mathrm{MPP}^{+}$in the dialysate significantly decreased the level of the DA metabolite DOPAC, while administration of higher $\mathrm{MPP}^{+}$concentrations resulted in no significant change.
\end{abstract}

Keywords: 1-Methyl-4-phenylpyridinium ion $\left(\mathrm{MPP}^{+}\right)$, Monoamine oxidase (B-form), Parkinsonism

Parkinsonism is induced in various species by the systemic administration of the neurotoxin 1-methyl-4phenyl-1,2,3,6-tetrahydropyridine (MPTP), which selectively destroys the nigrostriatal dopamine (DA) neurons $(1,2)$. Many studies indicated that the actual neurotoxin is a metabolite of MPTP, 1-methyl-4-phenylpyridinium ion $\left(\mathrm{MPP}^{+}\right)$, which is formed in a reaction catalyzed mainly by the B-form of monoamine oxidase (MAO-B, EC 1.4.3.4) in the brain (3-5). In addition to the finding that $\mathrm{MPP}^{+}$is produced by MAO-B catalysis, both MPTP and $\mathrm{MPP}^{+}$were found to dosedependently inhibit rat striatal and forebrain MAO activity (5). This enzyme has a key role in the induction of parkinsonism in humans after administration of MPTP because of the different localizations of MAO-A and MAO-B activity in various human brain areas as compared to rodent species (6). The MAO inhibitory action may explain the decrease in the concentrations of the DA metabolite 3,4-dihydroxyphenylacetic acid (DOPAC) without concurrent changes in DA levels in the striatum after MPTP administration to rats (7). Determination of the 3-methoxytyramine (3-MT) level in an in vivo experiment is very important because 3-MT is an indicator of the amount of DA released into the synaptic cleft (8). In this paper, we investigated the effect of $\mathrm{MPP}^{+}$on the extracellular DA and its metabolites after perfusion of $\mathrm{MPP}^{+}$into rat striatum.

Male Sprague-Dawley rats ( 350 to $450 \mathrm{~g}$ ) were anesthetized with chloral hydrate $(400 \mathrm{mg} / \mathrm{kg}$, i.p.) and prepared for intracranial microdialysis brain perfusion. The microdialysis probe (Fig. 1) was made from a $22-\mathrm{G}$ needle and microliter pipette tip. The plastic hub of the needle and the point of the microliter pipette tip were removed, and its stainless steel tube was cut to an appropriate length. This tube and a fused slica tube (470- $\mu \mathrm{m}$ o.d. $\times 350-\mu \mathrm{m}$ i.d.) were glued in place with epoxy resin. The flexible fused silica tubes $(150-\mu \mathrm{m}$ o.d. $\times 75-\mu \mathrm{m}$ i.d., EICOM) were supported by a metal tube. One of the open ends of a tubular dialysate membrane $(220-\mu \mathrm{m}$ o.d., $10-\mu \mathrm{m}$ wall width., $50,000 \mathrm{MW}$ cut-off; Cellulose hollow fiber) was sealed with the same resin. The tubular membrane was passed over the fused silica until the tip of the silica was $0.2 \mathrm{~mm}$ or less from the sealed end of the dialysis tubing. Finally, the joint between the membrane and the big silica tube was sealed with the resin under the dissecting microscope. A microdialysis probe ( $2 \mathrm{~mm}$ exposure) was stereotaxically placed in the striatum (stereotaxic coodinats: A: $1.0, \mathrm{R} / \mathrm{L}: 2.5, \mathbf{H}:-7.0 \mathrm{~mm}$ from the dura matter) (9). $\mathrm{MPP}^{+}$was purchased from Research Biochemicals, Inc. (USA). The drugs were dissolved in the Ringer solution containing $147 \mathrm{mM} \mathrm{NaCl}, 2.3 \mathrm{mM} \mathrm{CaCl}_{2}$, and 


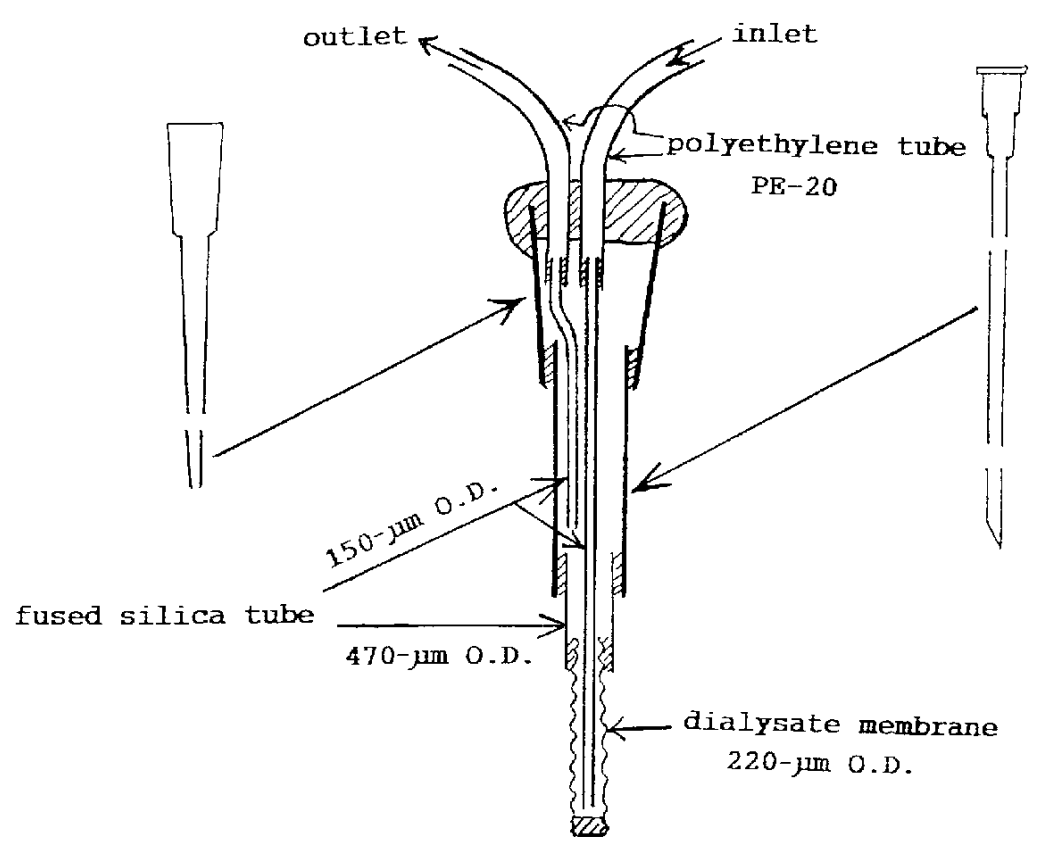

Fig. 1. Schematic diagram the construction of the microdialysis probc. diagonal: epoxy resin.

$4 \mathrm{mM} \mathrm{KCl}, \mathrm{pH} 6.0$ for perfusion $(1 \mu \mathrm{l} / \mathrm{min})$ through the microdialysis probe into the striatum. After the scheduled washout with the Ringer solution, $\mathrm{MPP}^{+}$(1 to $10 \mathrm{mM}, 1 \mu \mathrm{l} / \mathrm{min}$ ) was infused for $15 \mathrm{~min}$ in order to evoke the release of ${ }^{\prime} \mathrm{DA}$. The dialysate $(1 \mu \mathrm{l} / \mathrm{min})$ was collected every $15 \mathrm{~min}$ into $15 \mu \mathrm{l}$ of ice-cold $0.1 \%$ $\mathrm{Na}_{2}$ EDTA in $0.1 \mathrm{~N} \mathrm{HClO}_{4}$ and assayed immediately for DA, DOPAC, and 3-MT by a high performance liquid chromatograph with an electrochemical (HPLC-EC) procedure. Our microdialysis probe was tested in vitro to calculate the recovery of monoamines and metabolites through the membrane under various conditions. The inlet side of the microdialysis probe was connected by a PE-20 (1.09-mm o.d.) polyethylene tube to a $1 \mathrm{ml}$ syringe which was drive by a IP-2 microinfusion pump (BRC, Japan). The outlet side of the probe was connected to the same tube and placed into a small collecting tube. The probe was perfused with Ringer solution. The dialysis probe was then immersed into a Ringer solution. The recoveries of $10^{-7} \mathrm{M}$ DA, DOPAC and 3-MT were about 20,30 and $20 \%$, respectively, at the flow rate of $1 \mu \mathrm{l} / \mathrm{min}$. The dialysate samples were immediately injected for analysis into a HPLC-EC equipped with a WE-GC glassy carbon electrode (EICOM). The working electrode was set at a detector potential of $0.75 \mathrm{~V}$. Monoamine and metabolites were separated on an Eicompak MA-50DS column $(5 \mu \mathrm{m}$, $4.6 \times 150 \mathrm{~mm}$; EICOM). Each liter of mobile phase contained $1.5 \mathrm{~g}$ heptane sulfonic acid sodium salt (Sigma
Chemical Co., St. Louis, MO, USA), $0.1 \mathrm{~g} \mathrm{Na} 2$ EDTA, $3 \mathrm{ml}$ triethylamine (Wako Pure Chemical Industries, Ltd., Japan), $125 \mathrm{ml}$ acetonitrile (Wako) dissolved in $\mathrm{H}_{2} \mathrm{O}$. The $\mathrm{pH}$ of the solution was adjusted to 2.8 with approximately $3 \mathrm{ml}$ phosphoric acid (Wako) and filtered through a millipore filter before the additional of acetonitrile. Flow rates between 0.7 and $1.5 \mathrm{ml} / \mathrm{min}$ allowed the samples to be assayed within $20 \mathrm{~min}$. Results were reported as the mean and S.E.M. of the total output during a 120 -min period.

It has been reported that $\mathrm{MPP}^{+}$produces a sustained massive DA over flow $(10-12)$. DA levels especially in the brain regions (putamen, caudate nucleus and substantia nigra zona compacta) are high. The level of total DA in the brain dialysate increased dose-dependently following the administration of $\mathrm{MPP}^{+}$(1 to $10 \mathrm{mM}$, Fig. 2). Moreover, the level of 3-MT, which is an indicator of the amount of DA released, greately incrcased dose-dependently following the administration of $\mathrm{MPP}^{+}$. These data clearly indicated that the level of DA release was dose-dependently increased by $\mathrm{MPP}^{+}$. The present data also indicate a good correlation between the levels of released DA and increased 3-MT in the dialysate (8). However, the level of the oxidized DA metabolite DOPAC in the dialysate significantly decreased following the administration of only $1 \mathrm{mM}$ $\mathrm{MPP}^{+}$, which have resulted from the inhibition of presynaptic MAO activity by the high concentration of $\mathrm{MPP}^{+}$. Kinemuchi et al. (13) suggest that $\mathrm{MPP}^{+}$is an 


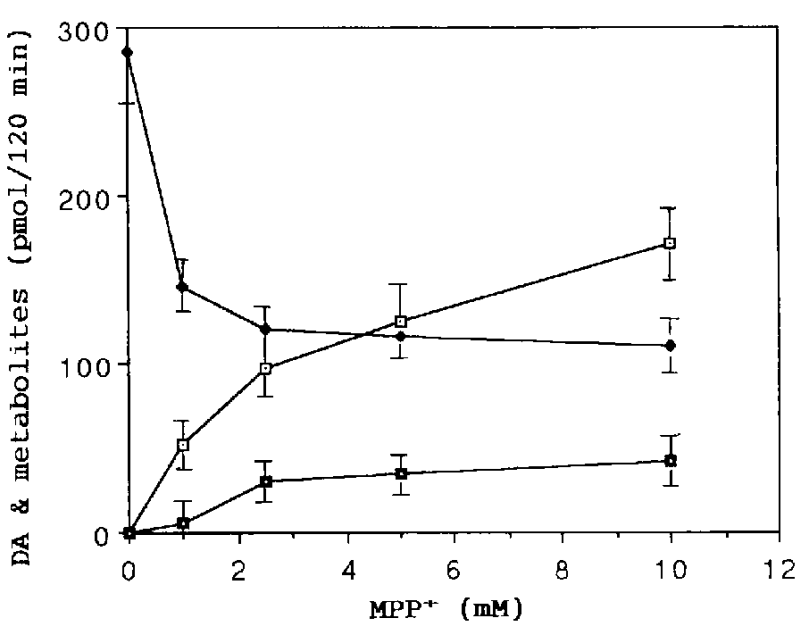

Fig. 2. Cumulative dose-response curve of $\mathrm{MPP}^{\dagger}$ for the total efflux (during a 120-min period) of DA $(\square)$, DOPAC $(\checkmark)$ and 3MT ( $\square$ ) from the rat striatum in vivo. The striatum of anesthetized rats (chloral hydrate, $400 \mathrm{mg} / \mathrm{kg}$, i.p.) was perfused with Ringer's solution $(1 \mu \mathrm{l} / \mathrm{min})$ through the probe for $3 \mathrm{hr}$ prior to $\mathrm{MPP}^{+}$administration. The pre-drug levels of DA, DOPAC and 3-MT were $0,36.11 \pm 4.69$ and 0 pmols $/ 15 \mathrm{~min}$, respectively. After a 60 -min washout with Ringer's solution, $\mathrm{MPP}^{+}(1-10 \mathrm{mM})$ was infused into the striatum for $15 \mathrm{~min}$. Brain dialysate was collected every 15 min into ice-cold $0.1 \% \mathrm{Na}_{2}$ EDTA in $0.1 \mathrm{~N} \mathrm{HClO}_{4}$ and immediately assayed for DA, DOPAC and 3-MT by an HPLC-EC procedure. Each value represents the mean and S.E.M. of five animals.

inhibitor of both MAO-A and MAO-B. The level of DOPAC was not changed when the $\mathrm{MPP}^{+}$concentration was increased further, up to $10 \mathrm{mM}$. This finding of no further increase in the DOPAC levels by higher concentrations of $\mathrm{MPP}^{+}$may be due to either the complete inhibition of the MAO activity by $1 \mathrm{mM} \mathrm{MPP}{ }^{+}$or lack of the substrate DA, which may not be available for this enzyme after its release and/or both.

\author{
Acknowledgments \\ We are grateful to $\mathrm{Mr}$. H. Nishino (EICOM) for his helpful \\ discussions.
}

\section{REFERENCES}

1 Langston, J.W. and Irwin, I.: MPTP: Current concepts and controversies. Clin. Neuropharmacol, 9, 485-507 (1986)

2 Aiuchi, T., Shirane, Y., Kinemuchi, H., Arai, Y., Nakaya,
K. and Nakamura, Y.: Enhancement by tetraphenylboron of inhibition of mitochondrial respiration induced by 1-methyl-4phenylpyridinium ion $\left(\mathrm{MPP}^{\dagger}\right)$. Neurochem. Int. 12, 525-531 (1988)

3 Chiba, K., Trevor, A. and Castagnoli, N., Jr.: Metabolism of the neurotoxic tertiary amine, MPTP, by brain monoamine oxidase. Biochem. Biophys. Res. Commun. 120, 574-578 (1984)

4 Markey, S.P. and Schmuff, N.R.: The pharmacology of the parkinsonian syndrome producing neurotoxin MPTP (1methyl-4-phenyl-1,2,3,6-tetrahydropyridine) and structurally related compounds. Med. Res. Rev. 6, $389-429$ (1986)

5 Kinemuchi, H., Fowler, C.J. and Tipton, K.F.: The neurotoxicity of 1-methyl-4-phenyl-1,2,3,6-tetrahydropyridine (MPTP) and its relevance to parkinson disease. Neurochem. Int. 11, 359-373 (1987)

6 Riederer, P. and Youdim, M.B.H.: Monoamine oxidase activity and monoamine metabolism in brain of parkinsonian patients treated with 1-deprenyl. J. Neurochem. 46, 13591365 (1986)

7 Bocchetta, A., Piccardi, M.P., Del Zompo, M., Pintus, S. and Corsini, G.U.: 1-methyl-4-phenyl-1,2,3,6-tetrahydropyridinc: correspondence of its binding sites of monoamine oxidase in rat brain, and inhibition of dopamine oxidative deamination in vivo and vitro. J. Neurochem. 45, 673-676 (1985)

8 Kato, T., Dong, B., Ishiki, K. and Kinemuchi, H.: Brain dialysis: In vivo metabolism of dopamine and serotonin by monoamine oxidase A but not $B$ in the striatum of unrestrained rats. J. Neurochem. 46, $1277-1282$ (1986)

9 Paxinos, G. and Watson, C.: The Rat Brain in Stereotaxic Coordinates. Academic Press, Sydney (1982)

10 Miyake, H. and Chiueh, C.C.: Effects of $\mathrm{MPP}^{+}$on the release of serotonin and 5-hydroxyindoleacetic acid from rat striatum in vivo. Eur. J. Pharmacol. 166, 49- 55 (1989)

11 Ozaki, N., Nakahara, D., Kaneda, N., Kiuchi, K., Okada, T., Kasahara, Y. and Nagatsu, T.: Acute effects of 1-methyl4-phenylpyridinium ion (MPP ${ }^{\dagger}$ ) in dopamine and serotonin metabolism in rat striatum as assayed in vivo by a microdialysis technique. J. Neural Transm. 70, 241-250 (1987)

12 Rollema, H., Kuhr, W.G., Kranenborg, G., De Vries, J. and Van Den Berg, C.: MPP $^{+}$-induced efflux of dopamine and lactate from rat striatum have similar time courses as shown by in vivo brain dialysis. J. Pharmacol. Exp. Ther. 245, $858-$ 866 (1988)

13 Kinemuchi, H., Arai, Y. and Toyoshima, Y.: Participation of brain monoamine oxidase $B$ form in the ncurotoxicity of 1-methyl-4-phenyl-1,2,3,6-tetrahydropyridine: relationship between the enzyme inhibition and the neurotoxicity. Neurosci. Lett. 58, 195-200 (1985) 